\title{
Las figuras heroicas de la revolución en los historiadores protomarxistas*
}

Enrique Rajchenberg $S$.

FE-UNAM

INTRODUCCIÓN

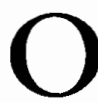

bjetos del desdén o de la burla por parte del gremio de los historiadores, los autores mexicanos de la llamada escuela socialista han sido proscritos de los states of the art de la historiografia nacional. Después de sesenta años de discusión metodológica, de apertura de archivos y de consolidación académica de la historia, la obra de estos autores que nacieron prácticamente con el siglo, parece excesivamente esquemática y simplista. A veces los historiadores de

*El autor agradece los comentarios críticos y sugerencias a este artículo realizados por Eugenia Meyer. Evidentemente, el texto y sus errores caen en el ámbito de mi responsabilidad. hoy olvidan que "toda obra histórica [...] es superable ${ }^{n 1} y$, por tanto, no simplemente desechable. Obviar las determinaciones históricas de la producción historiográfica es, sin embargo, un pecado más grave que el esquematismo y la simpleza de argumentos.

He agrupado bajo el término de protomarxistas a cinco autores (Luis Chávez Orozco, Agustín Cue Cánovas, José Mancisidor, Rafael Ramos Pedrueza y Alfonso Teja Zabre) que armados de algunos jirones de materialismo histórico se dieron a la tarea, en los decenios del treinta y cuarenta, de proponer una lectura de la historia di-

1 Sánchez Quinta:aar, “Tres”, 1977, p. 37. El presente ensayo se originó en la lectura del artícu. lo citado y en ese sentido es tributario de éste. 
ferente a la dominante en su época. Con ese arsenal teórico escasamente estudiado y reflexionado, su objetivo inicial no podía ser alcanzado cabalmente. No habían saldado cuentas con su conciencia historiográfica anterior como para establecer una ruptura epistemológica definitiva.

El objeto de este ensayo consiste precisamente en analizar cómo los protomarxistas retomaron, tal vez de manera inconsciente, una de las dimensiones de la interpretación histórica que desearon desterrar. Me refiero a la concepción heroica de la historia. Bajo este aspecto, el estudio está restrin. gido a los héroes de la revolución mexicana.

Si bien los elementos teóricos que permiten delimitar el objeto de estudio serán vertidos a lo largo del ensayo, se impone una definición inicial de la heroización de la historia. Desde mi punto de vista, se trata de la exaltación de ciertas cualidades, presentes sólo en algunos hombres, a las cuales se les atribuye un reconocimiento social transhistórico. Más específicamente, consiste en la explicación del queha. cer histórico por medio de la sola acción de determinados individuos.

La heroización de la historia constituye una astucia del poder, puesto que a la sociedad se le confiere el papel de seguidora de los senderos andados por el héroe. Así como el pasado se halla consignado en el discurso heroico por la pasividad de la sociedad, el devenir igualmente le es arrebatado y expro. piado, sancionando la frontera entre lo posible y lo imposible.

Los protomarxistas escapan parcialmente a esta definición porque sus posturas teóricas los obligan a considerar determinaciones objetivas que se sitúan más allá de las cualidades subjetivas de ciertos individuos como únicos elementos explicativos del pasado. En cambio, su limitado o nulo acceso a las fuentes primarias y su rala maestría para hacer de las propuestas mar. xistas principios heurísticos de la investigación los llevan a heroizar la historia.

Las visiones heroicas de la historia pueden ser consignadas como cofundadoras de mitos y éstos son un nivel de la realidad, una modalidad de la realidad pensada. En parte, los hombres actúan conforme a lo que creen y a veces en lo que creen es en los mitos. Ello no hace a éstos una simple mentira. Por lo tanto, no considero correcta la contraposición absoluta entre mito y realidad, frecuentemente utilizada. Por esa razón no procederé tampoco a desmentir a los autores como si pudie. ra confrontar lo que dicen que sucedió con lo que realmente aconteció. Interesa aquí únicamente el modo en que determinados personajes históricos son heroizados.

El ensayo comete dos injusticias con los cinco protomarxistas, justificadas únicamente por la necesidad de exponer más fluidamente los argumentos analíticos. Por una parte, juzga a los autores como si fueran historiadores, cuando en realidad no era la actividad profesional principal de ninguno de los cinco. Por otra, al limitarse a sus obras sobre la revolución, no da cuenta de la fecundidad de sus inves. tigaciones acerca de otras épocas; el caso más notorio sería el de Chávez Orozco. 
La investigación del pasado sólo se justifica si interrogamos al presente, si lo problematizamos gracias al conocimiento del pasado. A su vez, la acción política es la que nos permite tender un puente hacia el futuro e irlo construyendo. Para los protomarxistas, comprometidos prácticamente con un ideal político, la eficacia de la investigación y de la difusión de la historia era evidente. Algunos de ellos no dominaban el oficio de historiar, pero los cinco sabían para qué historiar.

El ensayo contiene tres partes. La primera se refiere a los determinantes históricos de la producción de los protomarxistas a partir de dos ángulos. Uno, el del debate intelectual de la época; dos, el de la coyuntura económica y política que vivieron. La segunda parte concierne a las interpretaciones que nuestros autores elaboraron acerca del movimiento revolucionario. La última y central consiste en su análisis de los héroes.

\section{MARX EN MÉXICO}

El cardenismo fue vivido por un sector de la intelectualidad mexicana como un reencauzamiento de la revolución en la senda iniciada en 1910 y temporalmente abandonada durante los diez años del régimen, constitucional o tras las bambalinas del poder, de Plutarco Elías Calles. Las movilizaciones populares, el reparto agrario, pero sobre todo la expropiación petrolera senta. ron las bases de la convicción de que el país ascendia aceleradamente por los peldaños de la escalera socialista.

Dos hechos coadyuvaron a cimen- tar esta percepción de la realidad. El primero consistió en la imagen difundida por la Unión Soviética acerca de los éxitos de la primera revolución socialista en el mundo. Pero no sólo fue la imagen publicitada sino que, en algunos casos, los viajes realizados por algunos a la URSS se conjugaron con una visión verdaderamente apologética de lo que acontecía en la patria de Lenin. Se vivían los años heroicos de la revolución rusa y ellos dejaban su huella grabada en la conciencia de los socialistas mexicanos. ${ }^{2}$

El segundo, igualmente generado en la URSS, se refiere al horizonte teórico dominante de la izquierda socialista. Desde la segunda mitad de los años veinte, la Tercera Internacional difundiría sus tesis acerca del fascismo como expresión política de la inexorable decadencia del capitalismo. El totalitarismo represivo de Italia y Alemania, caracterizado por Ramos Pedrueza como un "retroceso hacia el medioevo", serian el indicador más evidente de la incapacidad de gobernar de la burguesía. Aunque algunas voces disidentes se alzarian demostrando que el fascismo era en realidad la forma política que asumía la reestructuración capitalista ante la crisis del liberalismo y de la economía de libre competencia, las tesis de Dimitrov, portavoz del Partido Comunista de la Unión Soviética (PCUS), vendrían a ser las predominantes. De este modo, los puntos de vista opositores -los de Gramsci y Körsch, entre los más con-

2 "El movimiento más profundo que ha sacudido a la humanidad", dice Ramos Pedrueza, "es la revolución rusa, generada por la teoría económica de Carlos Marx". Ramos Pedrueza, Suge. rencias, 1932 , p. 3 . 
notados- se convertirían en una suerte de marxismo crítico.

La crisis económica iniciada en 1929 revigorizaría las tesis del PCUS. Ahora correspondería al economista Varga proclamar el inminente colapso general del capitalismo y el igualmente próximo advenimiento natural del so. cialismo en escala planetaria.

El pCus profetizaba el futuro $y$, en México, el régimen cardenista parecía confirmarlo: había que impulsar los contenidos progresistas de la política del régimen y prepararse para la sociedad sin clases. El marxismo se erigía, por consiguiente, en la construcción doctrinal más adecuada para el momento.

Junto con las profecías del PCus llegaba a México el paradigma marxista a copiar. Se trataba de su expresión más vulgarizada, en que se reducía la economía a la preeminencia del factor económico sobre otros niveles de la realidad. ${ }^{3}$

Esta oleada de marxismo que arribaba a tierras tropicales no podía desatar una discusión teórica, una especie de marxología, sino un aprendizaje veloz y dogmático de la escasa literatura marxista disponible en español para su inmediata aplicación al caso mexicano. El Manifiesto del Partido Co-

3 "La presente colección pretende proporcionar a la niñez una explicación de los fenómenos sociales, subordinándolos al factor económico. En otros términos, se trata de exhibir ante la niñez el proceso histórico fatalmente condicionado por la evolución de los medios de produc. ción". Chávez Orozco, Patria, 1951, p. 7.

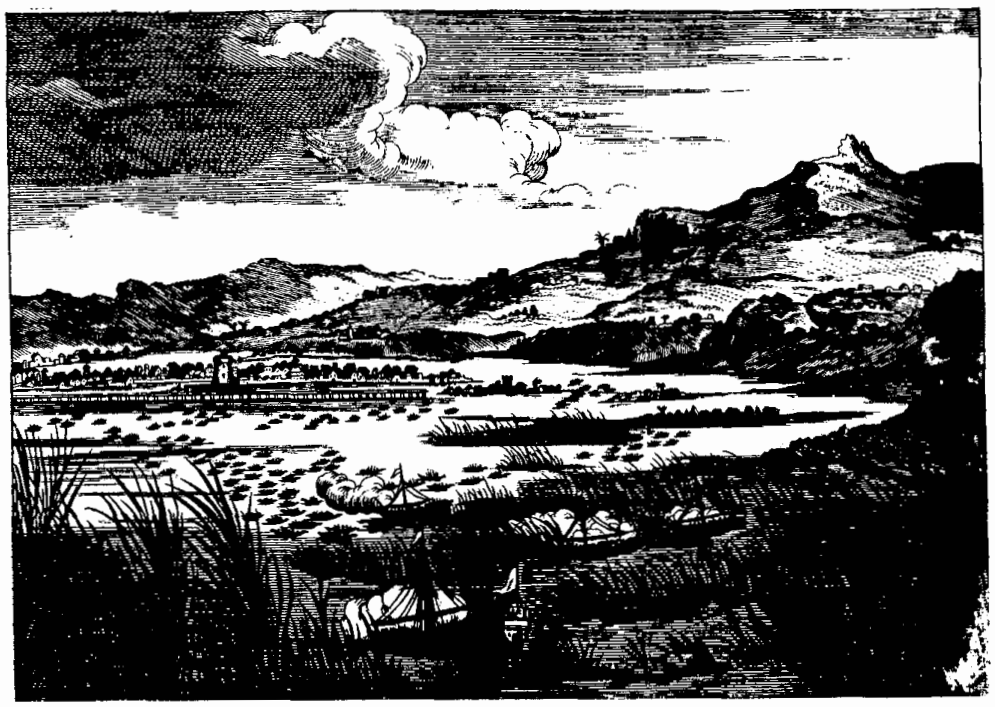


munista era conocido de tiempo atrás al igual que el famoso Prólogo a la Contribución a la crítica de la economía política, pero El capital y los Grundrisse eran totalmente desconocidos. Cuando Mancisidor escribe su pequeña obra titulada Marx, se consagra a exponer los hitos de una vida ejemplar, salpicados por algunas citas del biografiado. Exalta las cualidades intrinsecas del personaje y su capacidad para ignorar las apremiantes necesidades insatisfechas. ${ }^{4}$ Se trata de la construcción de una figura heroica, lograda mediante la atribución a un hombre de propiedades fuera de serie y que, como veremos posteriormente, acompañará la edificación de los héroes de la revolución mexicana por los protomarxistas.

Ello acrecentaba la utilización ideológica del marxismo al mismo tiempo que menguaba su eficacia científica para la explicación del cardenismo.

Si bien en este ensayo preocupa fundamentalmente analizar la construcción de figuras heroicas en la literatura historiográfica protomarxista, merece destacarse que el mismo paradigma tercerinternacionalista se difundió a otros ámbitos del quehacer intelectual. Por un lado, la economia, que hacía sus primeros pasos como disciplina autónoma en México, adop-

4 "Es desde niño un ser superior al que sus propios compañeros temen y respetan. Sus pa. dres, dentro de las disciplinas de la vieja sociedad, llegaron a concebir, respecto a él, las más risueñas esperanzas. Mas ¿qué relación se podía establecer entre los anhelos de aquellos buenos burgueses y Carlos Marx, que con su enorme talento parecía burlar la recta que ellos le señalaran?" Mancisidor, Marx, 1935, pp. 5-6. tó las tesis de Varga augurando el inminente fin del capitalismo. 5

Por otra, la literatura se alineó en los cánones emitidos en la URSS. La recomendación consistió en escribir literatura proletaria y revolucionaria, contrapartida escrita del realismo socialista en la pintura y la escultura: "La literatura revolucionaria debe tomar partido con la única clase que puede realizar el socialismo, es decir, con el proletariado". 6 En esta perspectiva, son cuestionados la obra de Mayakovski, el estridentismo de List Arzubide y la novela de la revolución "tan burgue. sa como la producción vanguardista".?

A partir de aquí se desarrolla una colección de textos literarios de las que fue pionero Mancisidor con $\mathrm{La}$ asonada en 1931. En ellas, destacan personajes capaces de sobreponerse a toda pena terrenal y consagrarse, con una voluntad sobrehumana, a la causa revolucionaria. $^{8}$

5 "En el año de 1929, se inició una gigantesca crisis económica que ha puesto de relieve el estado de decadencia del régimen capitalista." Cue Cánovas, Capitalismo, 1943, p. 232.

6 Turrent Rozas, Hacia, 1932, p. xı.

7 Ibid., p. xvi.

8 Uno de los ejemplos más ilustrativos es el protagonista de Transición, novela escrita por Álvaro Córdoba, a quien se le comunica que su madre agoniza pero él no deja de pensar en los últimos arreglos de la manifestación sindical mientras reflexiona acerca de "la sentimentalidad burguesa de nuestras religiones y la falsa moral de nuestros tiempos". Turrent Rozas, $\mathrm{Ha}$ cia 1932, p. 27. Durante la manifestación, la policía mata a varios obreros. El protagonista insiste ante sus compañeros llorosos: "Qué nos importa la vida de uno, de dos, de tres. ¿El dolor? No, el dolor no. Esta vida ya no es de lágrimas, de actitudes desesperadas." Ibid., p. 31. 
LA REVOLUCIÓN MEXICANA VISTA POR LOS PROTOMA RXISTAS

He agrupado bajo un mismo techo teórico, es decir el marxismo, a historiadores que con rigor conceptual y grados de adhesión diversos al materialismo histórico fueron activos catedráticos o escritores de historia durante los años treinta y cuarenta o aun después. Empero, la biografia de cada uno, su formación $y$ vocación profesionales divergen $y$ ello se reflejó en apreciaciones disímbolas acerca de la revolución de 1910 .

Con el objeto de distinguir con mayor precisión las propuestas interpretativas de los autores, conviene dividir el análisis en dos secciones; la primera referente a las causas de la revolución; la segunda, consagrada a su caracterización global.

\section{Causas de la revolución de 1910}

Para los autores que nos ocupan, el porfiriato representó una interrupción en el camino emprendido por el juarismo. Tiempos de retroceso y oscurantismo marcaron una discontinuidad en la historia de México durante 34 años.

Dos propósitos guían esta apreciación. Por un lado, la veneración del "gran Juárez", como lo nombrará Teja Zabre, o en general, de los liberales de 1857, muestra de incorruptibilidad, como proclama Ramos Pedrueza. ${ }^{9}$ Por otro, la clásica contrastación entre lo

9 "El oro que corrompe no menguó su honestidad; los éxitos y los infortunios no alteraron su heroica impasibilidad." Ramos Pedrueza, Sugerencias, 1932, p. 23. viejo y lo nuevo, entre el antes y el después que magnifica el ahora y sus bondades.

Bajo esta misma perspectiva, los más de tres decenios de vida oprobiosa bajo la dictadura porfirista condujeron inexorablemente a la revolución. Sin embargo, las posturas de cada autor son variadas frente a este aconteci. miento. En la versión más radical de Ramos Pedrueza, quien considera que el concepto de lucha de clases es la clave explicativa de la historia, la masa popular "se levantó contra el pequeño grupo oligárquico que se apoderaba de toda la riqueza nacional". 10

Aunque Ramos Pedrueza reconoce el impulso otorgado por Madero al levantamiento, éste parece emerger de la voluntad autónoma de las clases do. minadas. En cambio, Mancisidor reconoce que

los grupos políticos de extracción liberal, encabezando el descontento de las masas explotadas, iniciaron una campaña de franca oposición que había de dar al traste con el régimen porfirista. ${ }^{11}$

Al lado de estas dos visiones políticas, Teja Zabre formula la suya propia, reacio a analizar la revolución "porque está demasiado cerca de nosotros", y la de Chávez Orozco. El primero alude a una suerte de desequilibrio global en la sociedad porfirista tardía entre las fuerzas productivas y las formas políticas. Para Chávez Orozco el gobierno de Díaz 29.

10 Ramos Pedrueza, Sugerencias, 1932, p.

11 Mancisidor, Sintesis, 1976, p. 33. 
fue la consolidación de un régimen de producción feudal y la creación de un régimen de producción capitalista. De la contradicción en que entraron estos dos sistemas al madurar el uno (feudal) y al desarrollarse el otro (capitalista) surgió la revolución de 1910.12

Este objetivismo que permite a Chávez concebir a la revolución como resultado de fuerzas económicas le evitará tener que referirse a individuos de cualidades extraordinarias, como en el caso de los otros historiadores, con excepción de su admiración apologética a Cárdenas, que examinaré posteriormente.

\section{Caracterización de la revolución mexicana}

Sobre este punto nuevamente las definiciones discrepan entre sí, aunque todos ellos concuerdan, al calor del cardenismo o en su fase más tardía, que la revolución y sus motivos deben ser retomados. Su posterior "desilusión revolucionarian ${ }^{\text {13 }}$ no los conduce a un desencanto de tipo weberiano: sus textos de los cincuenta no son de amargura, sino al contrario, de reafirmación de los principios de la gesta de $1910 .^{14}$

12 Chávez Orozco, Historia, 1938, p. 171. p. 32.

13 Sánchez Quintanar, "Pensamiento", 1966,

14 Por ejemplo, Cue Cánovas apelará en 1959 a "estimular y fortalecer la aspiración imperiosa y enérgica del pueblo mexicano dirigida a reencauzar la revolución iniciada en 1910, para que ésta logre realizarse plenamente y en beneficio no de un sector privilegiado de la nación sino de las clases productoras del país", Cue Cánovas, Historia, 1959, p. 13.
Una de las caracterizaciones de la revolución que perdurará en la literatura marxista es la de Ramos Pedrueza, consistente en afirmar que se trató de una "revolución democrático burgue. sa latente desde 1810 , vitalizada por la reforma y desviada por la dictadura porfirista ${ }^{n} .15$ Puesto que Ramos Pe. drueza está convencido de que la revolución representa una vuelta más de la rueda de la historia en "su marcha progresiva, incontenible, hacia la construcción del socialismo", 16 el saldo es positivo para las clases dominadas de la sociedad burguesa. En ese sentido, destaca el abismo entre el campesino sumiso ante el amo y el capataz de la época porfirista y los "viriles y altivos ejidatarios e indómitos agraristas de $1940 "$, entre los obreros de 1910, extenuados por su trabajo, y los de 1940, "unificados en poderosas organizaciones y portadores de una cultura revo. lucionaria insospechada durante la dictadura porfirista" ${ }^{17}$ Sin embargo, advierte los límites de los derechos obreros consagrados en el artículo 123 constitucional, atribuye al Estado un carácter de clase burgués y su imposibilidad de convertirse en socialista mientras subsista el reconocimiento a la propiedad privada en la Constitución.

Teja Zabre asegura que los artículos $27,28,123$ y 130 constitucionales son una suerte de apéndice a un "sistema democrático mayoritario, individualista, burgués y liberal clásico" ${ }^{18}$ con-

15 Ramos Pedrueza, Lucha, 1941, p. 21.

16 Ibid., p. 462.

17 Ibid., p. 439.

18 Teja Zabre, Historia, 1961, p. 374. 
sistente en reformas socialistas. Pero, al referirse al 123, dirá que "es el paso más importante dado por un país para satisfacer las demandas de la clase trabajadora" ${ }^{19}$ Coherente con el finalismo histórico que sostiene, la revolución debe ser entendida como un impulso hacia la consumación de su evolución, misma que consistirá en el "establecimiento de un Estado socialista como panacea de todos los males". ${ }^{20}$

Mancisidor es más contundente aún en la caracterización propuesta. "La revolución mexicana - firma - fue así una revolución popular, burguesa, antifeudal y antimperialista ${ }^{n} .^{21} \mathrm{~A}$ pesar de su carácter de clase, la revolución habría rebasado los límites marcados por una revolución burguesa. Esta conclusión está provocada por su admiración irrestricta al artículo 123 que "rompió la armonía burguesa garantizando, explícitamente, los intereses de las masas trabajadoras" 22 y a la Constitución de Querétaro en su conjunto: "¿No es esta Constitución una fuerza revolucionaria que se proyectaba hacia todos los rincones del mun. do?"23

La defensa de la revolución a la que proceden los autores es evidente. Empero, ninguno de ellos considera, en virtud de su ideario socialista, que la revolución fuera un acto en que ya se hubieran alcanzado los principios originalmente propuestos en el levantamiento popular. Al contrario, se trata-

19 Teja Zabre, Panorama, 1939, p. 132. p. 150.

20 Sánchez Quintanar, "Pensamiento", 1966,

21 Mancisidor, Revolucion, 1977, p. 313.

22 Loc. cit.

23 Mancisidor, Sintesis, 1976, p. 71. ba de un punto en un largo proceso que era menester profundizar. En sintesis, la revolución seguía vigente y esta convicción la mantuvieron incluso en el poscardenismo, cuando la ilusión de un irresistible y veloz ascenso hacia la sociedad sin clases se disipaba rápidamente bajo los efectos del capitalismo norteamericano triunfante. Lamentablemente, nunca se percataron de que la historia no siempre camina del buen lado.

LOS SUJETOS DE VENER ACIÓN:

LOS HÉROES SEGÚN LOS PROTOMARXISTAS

Nuestros autores no escaparon a la proclividad de la historiografia dominante de confeccionar héroes a pesar de su desdén inicial por proceder a la manera tradicional. De hecho, su propósito de fundar una visión alternativa de la historia permanece a mitad de camino, dado su escaso conocimiento de la teoría que supuestamente iba a guiar el nuevo quehacer intelectual.

Una galería de héroes está sujeta a transformaciones en el largo plazo. Existe cierta permanencia asociada a la durabilidad de los mitos épicos en el imaginario colectivo cuya estructuración no se modifica con la coyuntura. En la medida en que los héroes devie. nen símbolos patrios, se convierten simultáneamente en valores absolutos, consiguientemente incuestionables y a prueba de las pequeñas sacudidas sociales. ${ }^{24}$ Las grandes conmociones provocan la incorporación de nuevas

24 "El mito transmite las creencias sociales sin que pasen por los tamices críticos". Segovia, Politizactón, 1977, p. 87. 
figuras heroicas que eventualmente desplazan a las anteriores, pero no necesariamente las suprimen.

Una de las expresiones de la batalla ideológica librada entre las viejas y nuevas fuerzas políticas se verifica precisamente en las própuestas divergentes de héroes. Para el nuevo régimen, resulta imperioso "rutinizar", fincar tradición en torno al poder político y su bloque de fuerzas emergentes. Reclamarse heredero e institución de valores absolutos como lo son los héroes consiste en el proceso mediante el cual el nuevo Estado puede, entre otros, apelar a la razón de Estado, tan indiscutible como los mismos héroes, para legitimar sus acciones.

Nuestros protomarxistas viven el momento de consolidación del régimen emanado de la revolución y mantienen con respecto a él, si no una adhesión incondicional, sí una actitud de colaboración. Ellos también se darán a la tarea de construir héroes.

\section{¿Quiénes son los héroes?}

Uno de los parteaguas ideológicos entre fuerzas contendientes está constituido por la inclusión o exclusión de personajes históricos en la galería heroica. Por supuesto, los insiders son los héroes; los outsiders, los antihéroes. Así, puede ser rastreada la sucesión de conflictos ideológicos habidos en el país a través de este juego entre individuos recordados y omitidos, tal como lo demostró Josefina Vázquez. ${ }^{25}$ 1970.

25 Véase Vázquez de Knauth, Nacionalismo,
En el caso que nos ocupa, la pugna entre "quién entra y quién sale" no adquiere grandes dimensiones en lo que concierne a los superhombres de la re. volución, puesto que dicho proceso empieza recién a historiarse en el mo. mento en que escriben los protomarxistas. Sin embargo, es preciso conocer quiénes se incorporan y por qué.

Los primeros, por orden de aparición, son los llamados precursores de la revolución: Camilo Arriaga, los hermanos Flores Magón, Juan Sarabia y Librado Rivera encabezan la lista con Ramos Pedrueza y Teja Zabre. A título de mártires ingresan a la galería heroica. Ramos Pedrueza añadirá el nombre de Pino Suárez y Teja a los "héroes sin nombre, obreros de Orizaba, mineros de Cananea, campesinos y ferrocarrileros". ${ }^{26}$

Cue Cánovas, por su parte, no oculta su alta estima hacia Ricardo Flores Magón. Para Cue, el fundador del Partido Liberal Mexicano (PLM) es el verdadero precursor de la revolución y, por tanto, le arrebata a Madero el nombramiento que la historiografia le había concedido. Destaca su combate al imperialismo y su muerte heroica como víctima de éste: "Nada doblegó su férrea voluntad; ningún sacrificio ablandó su alma; ninguna amenaza amedrentó su espíritu de luchador desinteresado y heroico". ${ }^{27}$ Mâs aún, termina desbancando a todos los personajes revolucionarios al declararlo "el más puro, desinteresado, noble y ge-

26 Teja Zabre, Historta, 1961, p. 37. En 1910, Teja fue premiado por un poema titulado "Los héroes anónimos".

27 Cue Cánovas, Historia, 1959, p. 295. 
neroso de los hombres de la revolución mexicana". ${ }^{28}$

Las biografias torturadas de estos hombres no los hacen menos héroes. Al contrario, decía Teja Zabre, no son héroes sólo "los afortunados que triunfan; también los que fecundan con sangre y con dolor la derrota que trascien$\mathrm{de}^{n} .29$

Llama la atención que estos autores, con excepción de Teja, no hayan heroizado a los actores colectivos en virtud del marco teórico del que se reclamaron tributarios. En tal sentido, su propósito de leer la historia como proceso de lucha de clases queda trunco. Las aspiraciones y demandas de las clases dominadas permiten revelar las grandes personalidades, pero no constituyen en sí sujetos, hacedores de la historia. Su sangre es derramada, sus anhelos son legítimos y cristalizan en nuevas condiciones laborales, agrarias, etc., pero cuya paternidad es atribuida a otros. De alguna manera, el pueblo constituye el coro de la rebelión, no la rebelión misma.

A partir de 1910 desfilan como héroes los ocupantes de la silla presidencial. Teja ve en Madero al "intérprete de los gritos exasperados de la población oprimida" ${ }^{30}$ y le adjudica "el prestigio de una popularidad ruidosa". ${ }^{31}$ Igualmente, Ramos Pedrueza define a Madero como "un hombre, humilde por el corazón, magnate por la fortuna, [...] [quien] reflejó la opinión pública, levantando a las masas contra

28 Ibid., p. 297.

29 Sánchez Quintanar, "Pensamiento", 1966, p. 113.

30 Teja Zabre, Panorama, 1939, p. 87.

31 Teja Zabre, Historia, 1961 , p. 370. aquella dictadura caduca y en plena descomposición". 32

En cambio, Mancisidor procede cautelosamente con el coahuilense. Identifica su posición de clase y los limites que ella implica para una prác. tica revolucionaria conforme a los intereses populares:

El capitalismo extranjero aprovechó para pedir a Madero el restablecimiento de la paz y el orden que Díaz hubiera establecido [...] Madero accedió a estas exigencias dominando algunos de estos movimientos por medios represivos. ${ }^{33}$

Ninguna heroicidad es atribuida al apóstol de la democracia por Mancisidor.

Conviene apuntar un denominador común a los historiadores que analizamos. Se trata del rasgo que permite a ciertos individuos elevarse al nivel de los héroes. En concordancia con su postura política, sólo son héroes aquellos que de alguna manera expresan los intereses de los sectores populares. És. te será el basamento de su heroicidad. Ello explica la discrepancia entre Mancisidor, por un lado, y Teja y Ramos, por otro, en cuanto a Madero.

Existen, sin embargo, algunos atenuantes. Es el caso del nacionalismo, considerado por principio ingrediente de una práctica política progresista. Esta postura se explica por su sentimiento antimperialista basado en los contenidos nacionalistas de la revolución y particularmente en el momento de fervor patriótico que vivieron los protomarxistas en marzo de 1938. 30 .

32 Ramos Pedrueza, Sugerencias, 1932, p. 33 Mancisidor, Síntesis, 1976, p. 43. 


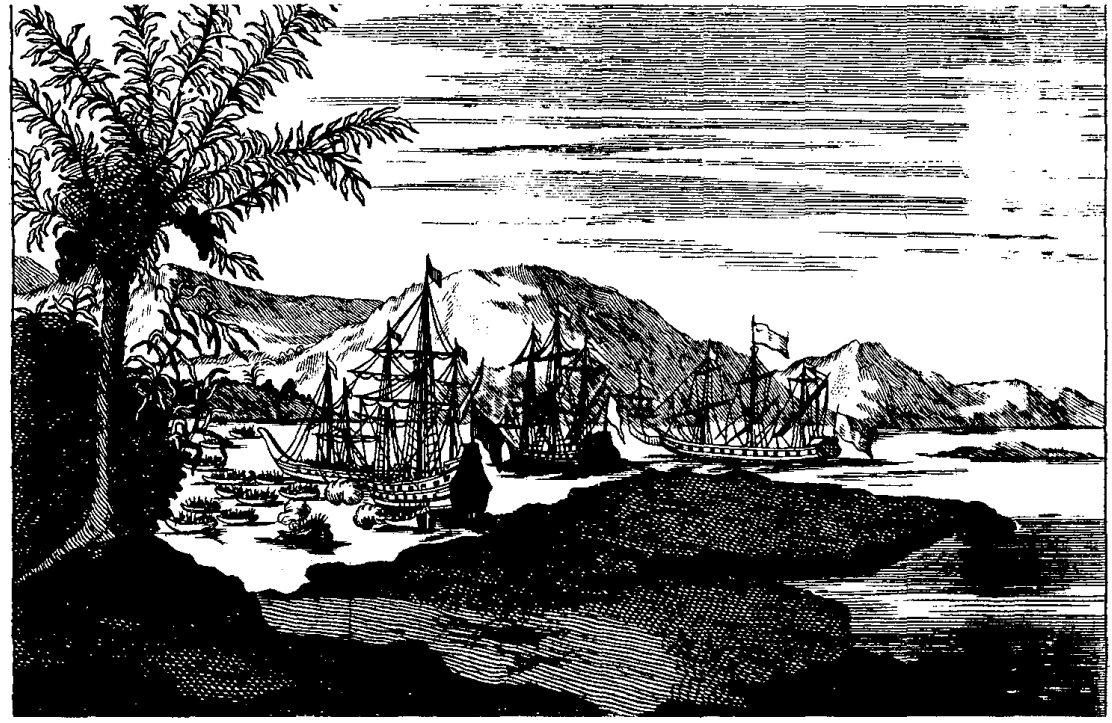

Puede entenderse entonces el trato benévolo concedido a Carranza. Por ejemplo, Ramos Pedrueza le reprochará el asesinato de Zapata, la "desaparición" de la Secretaría de Educación Pública y la imposición de Bonillas como candidato a la presidencia, pero

su política exterior fue digna de admira. ción [...] Ni el oro ni las amenazas de Wall Street quebrantaron su broncínea voluntad. Su altiva actitud frente al im. perialismo estadunidense fue ejemplifi. cadora. ${ }^{34}$

Álvaro Obregón suscita vivas simpatías, con excepción de Mancisidor 33.

34 Ramos Pedrueza, Sitgerencias, 1932, p. 33. 
agraria y obrerista de Obregón inaugura verdaderamente una nueva época en el país". ${ }^{37}$

Es Cárdenas quien se lleva el aplauso generalizado. Luis Chávez Orozco pierde la serenidad que caracteriza sus análisis históricos y forja una verdade. ra apología del general michoacano:

La aparición, más bien dicho, la revelación de Lázaro Cárdenas en la escena histórica de México sorprende por su oportunidad. Ningún hombre, en efecto, como él surgió en el preciso instante en que se le necesitaba como un factor de renovación social. ${ }^{38}$

Inmediatamente después, a manera de justificación, para no sucumbir en una visión heroica de la historia que combatió, agrega que Cárdenas, al igual que Díaz, Madero y Calles, no son sin producto de sus respectivas épocas; "sólo piensan y sienten y se acomodan de manera adecuada a las necesidades y oportunidades de su tiempon ${ }^{39}$ Posteriormente arremete: "Encarnación de la conciencia colectiva, personificación palpable de los anhelos de las masas, representativo del momento histórico en que vivimos, eso y no otra cosa, es Lázaro Cárdenas." 40

Teja Zabre, Ramos Pedrueza, Mancisidor y Cue Cánovas coinciden con Chávez Orozco. No se trata aquí de enjuiciar a nuestros historiadores por esta heroización sin límites que, en verdad, se comprende por la defensa

37 Cue Cánovas, Historia, 1959, p. 276.

38 Chávez Orozco, "Interpretación", 1937, p. 28. En mayúsculas en el original.

$39 \mathrm{Ibid}$.

$40 \mathrm{lbid}$. En mayúsculas en el original. política de un régimen, identificado según ellos con los objetivos del ideal socialista ya mundialmente en marcha. Interesa únicamente analizar cómo proceden a la heroización de Cárdenas.

Se reitera con dicha heroización el procedimiento tradicional de ensombrecer a los personajes previos para resaltar al actual. Calles se vuelve así el antihéroe por antonomasia. Por ejemplo, Chávez Orozco confronta las palabras de Díaz en la entrevista con Creelman, a quien expresa su deseo de no reelegirse, con la reafirmación del principio de no reelección hecha por Calles en su último informe de gobierno. De este modo, los antihéroes se asemejan entre sí; éstos y los héroes no son objeto de comparación y los hé. roes a su vez, no rivalizan entre sí.

Por este mismo medio, se enfatizan las rupturas históricas y la periodiza. ción de la historia puede ser cuatria. nual, luego sexenal:

El carácter regresivo de ese régimen [el callista] en sus postrimerias, y de los gobiernos que le sucedieron hasta 1934, determinó que la revolución se detuviera a mitad del camino [...] Con la gestión presidencial.del general Manuel Avila Camacho (1940-1946), en lo social, la revolución mexicana sufrió una nueva interrupción, continuada y acentuada durante la administración del señor Miguel Alemán. ${ }^{41}$

Restan dos personajes que nuestros autores no podían omitir, Villa y Zapata. El primero es definido por Ramos Pedrueza como el "defensor de los ex-

41 Cue Cánovas, Historia, 1959, pp. 276.278. 
plotados", 42 "producto fuerte, sangrante, dramático, de la torturada gleba mexicana, es dentro de la historia nacional, una inmensa y tempestuosa fuerza revolucionarian. ${ }^{43}$

Ramos se siente obligado a justificar y desmentir el lado oscuro de Villa, esto es, su dudosa moralidad, que fue precisamente evidenciada por los autores porfiristas o incluso por la intelectualidad revolucionaria con el objeto de rebajar su estatura. "Jamás se embriagó", "ni siquiera fumaba -dice Ramos-, su erotismo extremado, producto de su temperamento sanguíneo, lo impulsaba a la conquista de cuanta mujer le impresionaba". ${ }^{44}$

Mancisidor también se cree obligado a mencionar la misma dimensión de la personalidad de Villa, pero apela al perdón popular de sus faltas, "para recordar con su lucha y con su obra a uno de los más recios forjadores de la nacionalidad". ${ }^{45}$

Zapata es un personaje más limpio puesto que combina la defensa de los intereses de las clases oprimidas con una conducta moral por encima de toda sospecha. Por ello, el morelense puede aparecer como "alto ejemplo de abnegación y firmeza". ${ }^{46}$ Más aún, Za. pata combina otros dos elementos de la mayor heroicidad concedida a un individuo, su honestidad y su pobreza: "Desinteresado de bienes materiales, despreciando la riqueza, murió pobre,

42 Ramos Pedrueza, Lucha, 1941, p. 135.

43 Ibtd., p. 153.

44 lbid., p. 151.

45 Mancisidor, Revoluctón, 1977, p. 256.

46 Ramos Pedrueza, Lucha, 1941, p. 100. al grado de que sus familares quedaron en la miseria." 47

A estos dos héroes populares se les atribuye un rasgo que no se adjudica a otros héroes. Ambos poseerían cualidades innatas, manifiestas desde su niñez que los harian amantes naturales de la justicia y, consiguientemente, redentores de las clases oprimidas. Zapata, por ejemplo, se distinguió desde niño "por su carácter observadory reflexivo, y su amor a la verdad y a la justicia $^{n} .^{48}$ Villa, a su vez, sobresalió por su "gran inteligencia natural." 49

Muy a pesar de los protomarxistas, la referencia a las cualidades naturales de los héroes - recuérdese la biografía de Marx por Mancisidor-forjan la imagen de una predestinación que acompaña a algunos hombres para la realización de grandes obras. Otros hombres parecían estar encaminados por el buen sendero, pero las malas compañías los desviaron, como le sucedió al general Serrano: "La influencia materna, digna de respeto en general, tuvo un efecto nefasto para el hijo modelo y para el pueblo mexicano" ${ }^{50}$

\section{La honestidad, la incorruptibilidad y otras virtudes}

Los héroes de los protomarxistas no son exaltados por su valentía guerrera.

47 Ibid., p. 103.

48 Ramos Pedrueza, Lucha, 1941, p. 100.

49 Mancisidor repite la anécdota divulgada por Germán List Arzubide acerca de Zapata, quien al ver llorar a su padre exclamó "con voz en que seguramente temblaba ya el encono" que recuperaría las tierras cuando fuera grandc.

50 Ramos Pedrueza, Lucha, 1941, p. 315. 
Las acciones bélicas de algunos de ellos no son insumo de su pedestal simbólico. Ello los diferencia de la épica oficial más pomposa. Son exaltados, en cambio, la honestidad, la incorruptibilidad, el nacionalismo y la defensa de las clases oprimidas.

Iniciemos por esta última virtud. Para los protomarxistas, la bipolaridad clasista de la estructura social se calcaría tal cual en el abanico de posiciones políticas. De este modo, tras los héroes siempre se encuentran las masas trabajadoras. En los conflictos sociales, como por ejemplo durante la rebelión delahuertista, Obregón tiene a los buenos con él y el ex secretario de Hacienda al clero, a la burguesía, etc. Asimismo, tras Calles se alinean los burgueses nacionales y extranjeros $y$, a partir de 1934, Cárdenas cuenta con el apoyo de las clases dominadas. La guerra cristera es rebajada, en consecuencia, al nivel de una contienda por pasiones religiosas. ¿Cómo explicar si no que un segmento importante de los "amolados" se pusiera del lado equivocado?

Pasemos a la diferenciación entre figuras heroicas que se delínea en nuestros autores. Hay héroes que pasan por debajo del arco del triunfo; son los ocupantes de la silla presidencial. Otros son protagonistas del dolor, la pobreza y la enfermedad; son los hombres cuya heroicidad se construye sobre su martirio. Pero todos ellos comparten una misma virtud, la incorruptibilidad y por esta razón algunos mueren en la pobreza. Consecuentemente, ésta deja de ser objeto del oprobio público, como sostenían los ideólogos porfiristas, y pasa a constituirse en fuente de orgullo: la pobreza es algo que se po- see con dignidad desde la cuna hasta la tumba.

Entre los héroes y los plebeyos, la distancia se va haciendo menos. Los héroes ya no son necesariamente individuos condecorados, cultos y con fortuna, sino que se parecen al pueblo. Esta semejanza hace a los héroes más aceptables $y$, por consiguiente, más fácilmente integrables a la cultura política popular. ${ }^{51}$

Para estos historiadores que vivie. ron el decenio del cuarenta, de conversión de jefes revolucionarios en prósperos hombres de negocios, se trataba no sólo de generar una nueva moral social en torno a la pobreza, sino también de denunciar a los advenedizos que traicionaban los principios de una revolución que ellos defendían y consideraban aún vigentes.

Los héroes, ha dicho Segovia, son creadores de la nacionalidad. Los héroes expuestos en este ensayo cumplen cabalmente esa función. En efecto, el nacionalismo es factor de cohesión social mediante la reproducción del sentimiento de pertenencia a una comunidad y dicho sentimiento se renueva a través de la veneración colectiva de sus héroes autóctonos. El mito requiere un rito. Existe, en consecuencia, un grado de religiosidad asociado a los héroes. La apropiación o la creación así como la organización de los rituales conmemorativos por el Estado, quien afirma gobernar en su nombre para preservar su tradición, viene

51 La Virgen de Guadalupe es la más popular en México no sólo porque su aparición tuvo lu. gar en este país, sino porque se reveló a un natural, no a un criollo o a un peninsular, y porque es morena. 


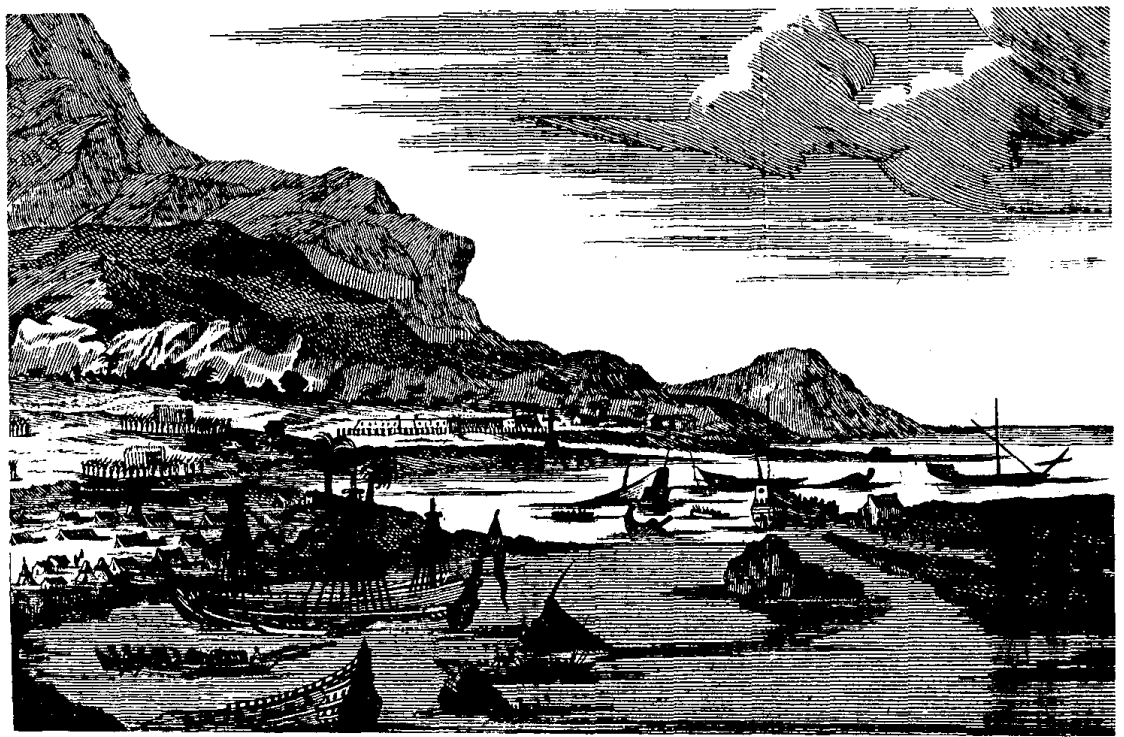

siendo uno de los pilares de la obediencia social recaudada por el Leviatán.

Concluyamos. Seguramente no era propósito de los protomarxistas legitimar la asfixia de la sociedad por ese Moloch que con el tiempo sería el Estado mexicano. Pero nuestros autores compartían con una buena parte de sus contemporáneos de semejante filiación política la certeza de que el Estado era una palanca poderosa de la emancipación social. Por ejemplo, Chávez Orozco, al referirse a las peculiaridades de la "revolución de 1935 . $1937^{n}$, distinta de la de 1910 , destaca que "se realiza desde el poder, con el apoyo de las clases proletarias". 52 p. 25 .

52 Chávez Orozco, "Interpretación", 1937, 
lectual que reafirmara el carácter bené. fico de la revolución era bienvenido.

El estatismo y la defensa de la revolución por los protomarxistas fueron los ingredientes que explican la admisión y difusión de sus textos incluso por el Estado thermidoriano que ellos tanto criticaban.

Lo que ciertamente no hicieron estos pioneros del marxismo en México fue llevar hasta el extremo la disociación entre los personajes ilustres y el contenido de sus prácticas como en las versiones heroicas más conservadoras de la historia. Ésta sí es una obra estatal que, a través de la homogeneización de los héroes, unifica a individuos y proyectos políticos irreconciliables en la misma cara de una moneda de 200 pesos (de izquierda a derecha, co. mo en las fotos, Zapata, Madero, Carranza y Villa). En última instancia, es el Estado quien opera la mediación que va desde la sanción del dinero como equivalente general de las mercancías, hasta la sanción de los héroes como referentes generales de las acciones políticas de los ciudadanos.

\section{BIBLIOGRAFIA}

-Châvez Orozco, Luis, "Interpretación marxista de Lázaro Cárdenas", en Joseph Freeman, Enrique Gutmann y Luis Chávez Orozco, Lazaro Cárdenas visto por 3 hombres, Masas, México, 1937. ,Historía económicaysocial de México, Botas, México, 1938.

Historia patria, Patria, México, 1951 (Colección de Textos de Historia para las Escuelas Primarias Mexicanas).

-Cue Cánovas, Agustín, Historia del capitalismo, Grafos, México, 1943.
México, 1959.

, Historia mexicana, Trillas,

-Mancisidor, José, Marx, Publicaciones del Departamento de Bibliotecas de la Secretaria de Educación Pública, México, 1935 (Biblioteca del Obrero y Campesino). , Sintesis histórica del movimiento social en México (1940), Centro de Estudios Históricos del Movimiento Obrero Mexicano, México, 1976. Historia de la Revolución Mexicana, 33a. ed., Costa-Amic, México, 1977.

-Ramos Pedrueza, Rafael, Sugerencias revolucionarias para la enseñanza de la historia, Universidad Nacional Autónoma de México, México, 1932. , La lucha de clases a través de la historia de México, Talleres Gráficos de la Nación, México, 1941.

-Sánchez Quintanar, Andrea, "El pensamiento histórico de Alfonso Teja Zabre", tesis de licenciatura, Facultad de Filosofia y Letras, Universidad Nacional Autónoma de México, 1966.

"Tres socialistas en la historiografía mexicana contemporánea", Anua. rio, núm. 2, Universidad Michoacana, Morelia, 1977.

-Segovia, Rafael, La politización del niño mexicano, El Colegio de México, México, 1977.

-Teja Zabre, Alfonso, Panorama historico de la Revolución Mexicana, Botas, México, 1939.

Historia de México. Una moderna interpretación, 4a. ed., Botas, México, 1961.

-Turrent Rozas, Lorenzo, Hacia una literatura proletaria, Ediciones Integra. les, Jalapa, 1932.

- Vázquez de Knauth, Josefina, Nacionalismo y educación en México, El Colegio de México, México, 1970. 